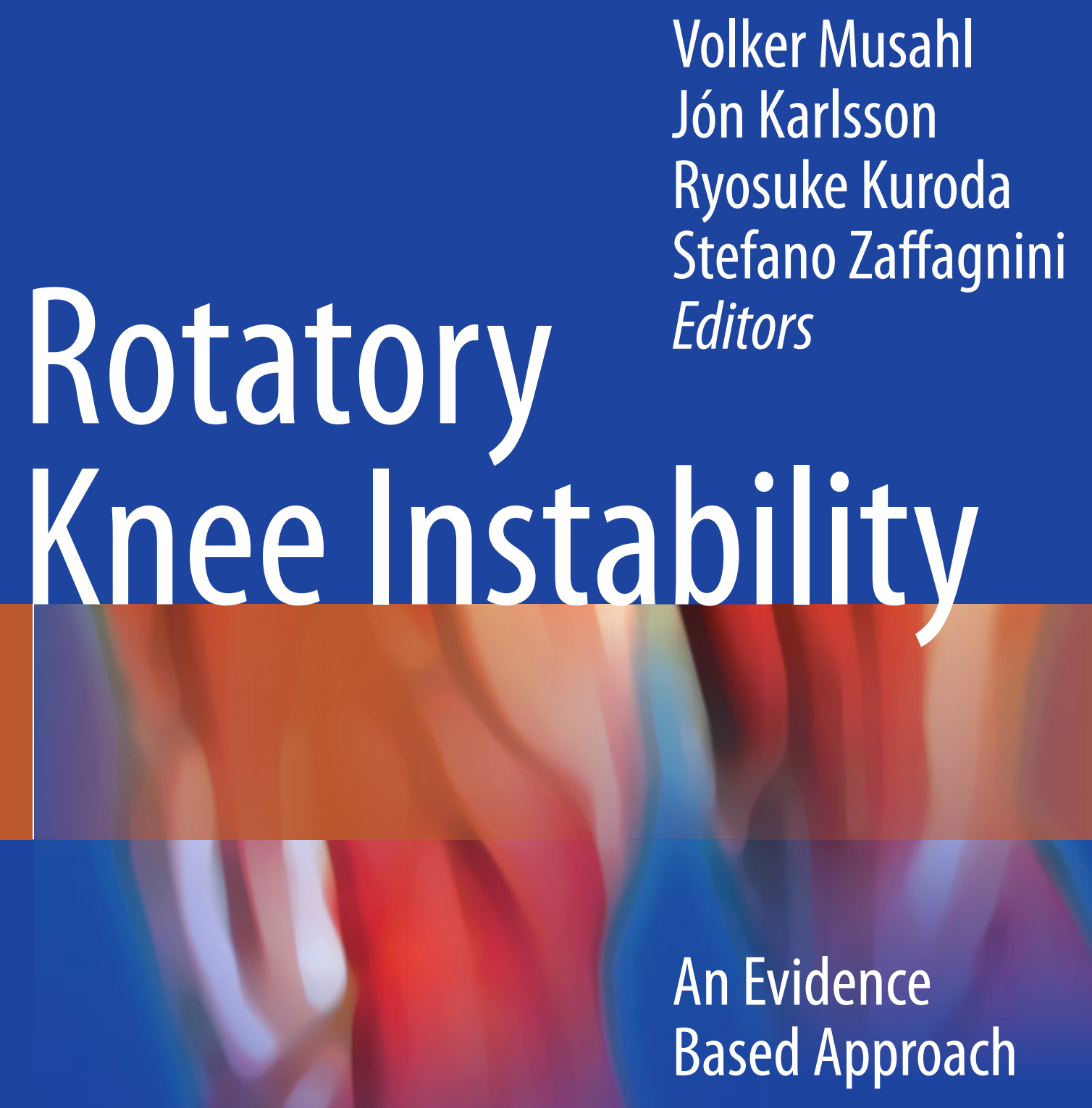

Springer 


\title{
MRI Laxity Assessment
}

\author{
Hélder Pereira, Sérgio Gomes, \\ José Carlos Vasconcelos, Laura Soares, \\ Rogério Pereira, Joaquim Miguel Oliveira, \\ Rui L. Reis, and Joao Espregueira-Mendes
}

\section{Contents}

5.1 Introduction

5.2 The Concept of Rotatory Instability of the Knee

5.3 Comprehensive Evaluation of ACL Tear on MRI

5.3.1 Acute ACL Tear

5.3.2 Chronic ACL Tear

5.3.3 Partial ACL Tear

5.4 Dynamic and Objective MRI

Assessment of the Knee: Porto-Knee

Testing Device (PKTD)

Conclusion

References 54

\footnotetext{
H. Pereira $(\bowtie)$

3B's Research Group - Biomaterials, Biodegradables and Biomimetics, University of Minho,

Braga, Portugal

European Institute of Excellence on Tissue Engineering and Regenerative Medicine, Avepark Parque de Ciência e Tecnologia, Zona Industrial da Gandra, Barco Guimarães 4805-017, Portugal
}

ICVS/3B's - PT Government Associated Laboratory, Barco Guimarães, Portugal

Ripoll y De Prado Sports Clinic - FIFA Medical Centre of Excellence, Murcia-Madrid, Spain

Orthopedic Department, Centro Hospitalar Póvoa de Varzim, Póvoa do Varzim - Vila do Conde, Portugal e-mail: helderduartepereira@gmail.com

49

\subsection{Introduction} for reconstruction or augmentation of ACL injuries $[38-40,50]$. Individualized ACL repair is now recommended by several authors depending on patient's characteristics, specific demands, and surgeons' experience $[1,42]$.

S. Gomes • J.C. Vasconcelos • L. Soares • R. Pereira Clínica do Dragão Espregueira-Mendes Sports Centre - FIFA Medical Centre of Excellence, Porto, Portugal

J.M. Oliveira • R.L. Reis • J. Espregueira-Mendes 3B's Research Group - Biomaterials, Biodegradables and Biomimetics, University of Minho,

Braga, Portugal

European Institute of Excellence on Tissue Engineering and Regenerative Medicine, Avepark Parque de Ciência e Tecnologia, Zona Industrial da Gandra, Barco Guimarães 4805-017, Portugal

ICVS/3B's - PT Government Associated Laboratory, Barco Guimarães, Portugal

Clínica do Dragão Espregueira-Mendes Sports Centre - FIFA Medical Centre of Excellence, Porto, Portugal 
Suboptimal outcomes following ACL repair can be related to an inexact diagnosis and inaccurate preoperative planning. Improved diagnostic capacities are in great need in order to assist in the choice for the best course of treatment for each patient. Several attempts have been made and are currently under development to enhance the capacity of imaging assessment. One of the recent trends is the possibility for dynamic evaluation either using radiographs [20, 51], ultrasound [17], or MRI [12, 25] in order to test simultaneously the functional capacity of the ligaments. Robotics [10, 64] and electronic devices [34] have also been proposed.

This work aims to describe the traditional features of MRI evaluation of ACL tears but also the evolving possibility for dynamic and objective quantification of knee laxity. This concept proposes to enhance the clinical evaluation tests by combining simultaneous MRI imaging assessment.

\subsection{The Concept of Rotatory Instability of the Knee}

Clinical examination is still one of the most important steps when evaluating the injured knee [41]. Laxity evaluation and grading is considered a key point to success $[2,19]$. The most frequently used clinical tests are the Lachman (considered the most sensitive) and the Pivot shift test (considered the most specific) [44]. However, manual clinical examination is difficult to quantify, as it is examiner dependent and lacks intra-tester reliability [2, 26, 27, 36, 53]. Several methods to achieve objective instrumented assessment of the Lachman test [24] have been used [41]. However, some concerns about poor correlation with clinical outcome have been reported [24].

However, the pivot shift has been considered more specific than the Lachman test [4], and it might also be useful in the clinical diagnosis of partial ACL tears [11]. Nevertheless, in a recent study, the clinical grading of the pivot shift has been considered as subjective and inconsistent [19]. In this study, weak correlations were found between the quantitative measurements and the clinical pivot shift grade [19]. Based on that results, the authors suggested to use a simple positive/negative grading and add a quantitative value to register the pivot shift [19]. Many descriptions of the maneuver have been proposed, and many devices have been developed in an attempt to objectively quantify the pivot shift test [36, 40, 41].

If the pivot shift test remains positive after ACL repair, this has been correlated with poor subjective and objective outcome. In such cases, lower rates of return to sports and higher development of degenerative changes have also been reported [21, 31]. One major limitation of the pivot shift test is that it is a non-weight-bearing examination and cannot mimic the true effect of rotatory knee laxity in dynamic weight-bearing conditions [39].

Bony morphology is another aspect, which is known to influence knee stability and the pivot shift phenomenon. Smaller lateral tibial plateau has been reported to be related to higher grade pivot shift test [36]. It has also been suggested that an increased degree of posterior-inferior tibial slope is related to higher pivot shift grade [6]. Moreover, it has also been reported that the distal femoral geometry can influence dynamic rotatory laxity [18].

Besides the bony morphology, features of the ligament itself are also involved in this pivot shift phenomenon. The posterolateral (PL) bundle of the ACL ligament was believed to be the primary responsible for controlling rotational stability; however, the anteromedial (AM) also plays a relevant role $[23,62]$. The relative contributions of each bundle are dependent on the knee flexion angle [62].

In terms of all the abovementioned, it is necessary to combine anatomical and functional assessment. The eradication of a positive pivot shift test is considered the most important goal of the ACL repair surgery. Therefore, the first step should be to improve the objective quantification of the pivot shift phenomenon.

MRI has proved its value in anatomic study of the knee. If the "power" of this imaging technology can be combined with the dynamic evaluation of the joint, this will surely provide improvements of pre- and postoperative assessment. Moreover, this dynamic evaluation using the MRI device should enable joint assessment in different degrees of flexion and combine anterior-posterior and rotational forces. 


\subsection{Comprehensive Evaluation of ACL Tear on MRI}

Previous studies have reported a general $78-100 \%$ sensitivity and 68-100\% specificity of MRI for the diagnosis of ACL tears [16, 47, 56, 61]. In recent studies an accuracy of approximately $95 \%$ has been reported [3]. The diagnosis of proximal, partial, or chronic tears has been considered as more challenging and accounts for most of the persistent errors in interpretation [3]. Sensitivity is also significantly decreased in cases of multi-ligament injury [3, 49]. Recently, 3-tesla imaging has improved the distinction of the AM and PL bundles; however, it has not significantly increased the MRI accuracy for detection of ACL injuries [60]. Concerning MRI analysis, about $70 \%$ of ACL tears occur in the middle part of the ligament, 7-20\% occur near its femoral origin, and only $3-10 \%$ are identified at the tibial insertion $[45,46]$.

MRI protocols for the knee joint are designed to yield diagnostic images of the ACL as well as the menisci, bones, articular cartilage, and other ligamentous structures of the knee. The requirements for optimal meniscus and cartilage imaging are more demanding than what is needed for diagnostic ACL imaging. In general, a protocol that enables proper imaging of the menisci and cartilage will also satisfactorily demonstrate the ACL. For that reason, several centers image patients in full knee extension, although the ACL is better evaluated with the knee in approximately $30^{\circ}$ of flexion [30].

T2 sequences are most relevant for the diagnosis of acute ACL ruptures [33]. However, in most centers, the regular protocol for knee MRI evaluation includes T2-weighted sequences (or protonweighted fat-suppressed) in 2-3 orthogonal planes and one T1-weighted sequence in either the sagittal or coronal plane $[14,33]$. Lately, fast spin echo fat saturation sequences have proven to be quicker and more sensitive to injury than conventional $\mathrm{T} 2$-weighted spin echo images and have been increasingly replacing these sequences [16].

When evaluating an MRI examination, the observer must be familiar with the "normal" and "abnormal" features and routinely inspect the ACL in all planes [16]. The method of acquisition of sagittal images for ACL study has varied over time. A frequent recommendation, in order to achieve images closer to the long axis of the ACL, is to perform sagittal oblique slices at $10-15^{\circ}$ perpendicular to a bicondylar line tangent to the posterior margins of the medial and lateral femoral condyles [16]. However, several centers now advise that the true sagittal plane (perpendicular to the bicondylar line) is superior for evaluation of the ACL and meniscus as well (Unpublished data, Mayo Clinic, Jacksonville, Fla. Presented at Society of Skeletal Radiology, March 2009).

\subsubsection{Acute ACL Tear}

The changes of the ACL tissue itself, which permit a high accuracy in the diagnosis of an acute tear, are considered the primary signs of ACL tear (Fact Box 1) [13, 29]. The axis of the ACL is abnormal if it is clearly more horizontal than a line projected along the intercondylar roof (Blumensaat line) on sagittal images (Fig. 5.1) [13]. An angle of less than $45^{\circ}$ of the long axis of the ACL relative to a line parallel to the tibial plateau, also known as "the ACL angle," is reported to be sensitive and specific for an ACL rupture [32].

\section{Fact Box 1. Summary of Primary and} Secondary MRI Signs of Acute ACL Tear

\begin{tabular}{l|l}
\hline $\begin{array}{l}\text { Primary signs } \\
\text { (enable the } \\
\text { diagnostic per se) }\end{array}$ & $\begin{array}{l}\text { Secondary signs (its } \\
\text { absence does not exclude } \\
\text { the diagnosis of ACL tear) }\end{array}$ \\
\hline $\begin{array}{l}\text { Non-visualization } \\
\text { of the ACL }\end{array}$ & $\begin{array}{l}\text { Pivot shift bone bruises/ } \\
\text { osteochondral fractures }\end{array}$ \\
\hline $\begin{array}{l}\text { Rupture of the } \\
\text { substance of the } \\
\text { ACL noticed by } \\
\text { abnormal increased } \\
\text { signal intensity }\end{array}$ & $\begin{array}{l}\text { Anterior translocation of } \\
\text { the tibia }\end{array}$ \\
\hline $\begin{array}{l}\text { ACL abrupt } \\
\text { angulation or wavy } \\
\text { appearance }\end{array}$ & $\begin{array}{l}\text { Segond fracture: high } \\
\text { association with ACL } \\
\text { injury }\end{array}$ \\
\hline $\begin{array}{l}\text { Abnormal axis of } \\
\text { the ACL }\end{array}$ & $\begin{array}{l}\text { Fracture of the tibial spine: } \\
\text { less reliably associated } \\
\text { with ACL tear }\end{array}$ \\
\hline
\end{tabular}



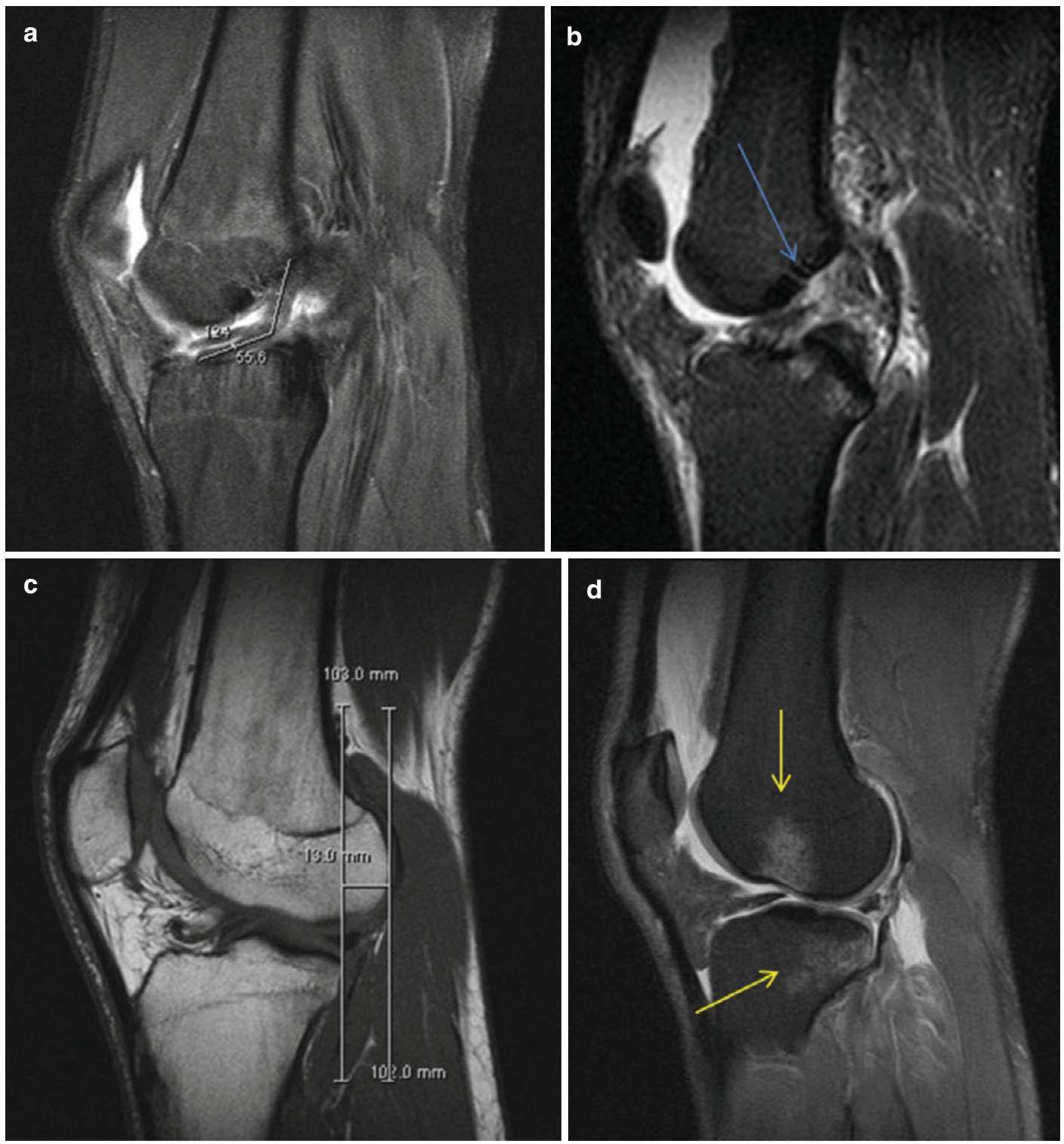

Fig. 5.1 Examples of primary signs of acute ACL tear: ACL abrupt angulation (a) and rupture of the substance of the ACL noticed by abnormal increased signal intensity (blue

A common finding of an acute ACL rupture is non-visualization of the ligament. Focal edema and/or hemorrhage are seen where the "normal" ACL is expected to be found. Enlargement and increased internal signal intensity, while preserving intact fascicles have been described as interstitial tear (or delaminated tear). This type of arrow) (b). Examples of secondary signs of acute ACL tear: anterior translocation of the tibia (10 $\mathrm{mm}$ in this example) (c) and bone femoral and tibial bruises (yellow arrows) (d) 
but are correlated to the injury mechanism (Fact Box 1). The absence of such signs does not exclude the diagnosis of ACL rupture [7, 16]. However, they are useful when primary signs are found to be ambiguous [7].

When a rotatory injury of the ACL occurs, there is a movement of external rotation of the lateral femoral condyle (LFC) relative to the fixed tibia. This way, the LFC causes an impact to the posterolateral tibial plateau, which might give origin to bone bruises and/or fractures of one or both bones [35]. The LFC bone bruise is usually found close to the anterior horn lateral meniscus. However, if such injuries occur at higher degrees of flexion, these bruises will be found more posteriorly. The tibial bone bruise/ fracture usually occurs at the posterolateral corner of the tibia [35].

Anterior translocation of the tibia indirectly suggests ACL insufficiency [9]. If this anterior translocation exceeds $5 \mathrm{~mm}$, an acute or chronic ACL tear is probable to be found [9]. A Segond fracture (Fig. 5.2) has a $75-100 \%$ association with ACL tear [46]. The Segond fracture is described as an elliptical, vertical, $3 \times 10-\mathrm{mm}$ bone fragment parallel to the lateral tibial cortex about $4 \mathrm{~mm}$ distal to the plateau [8]. These types of fractures have historically been attributed to traction avulsion of the middle third of the meniscotibial capsular ligament [8]. The iliotibial band and lateral collateral ligament complex might also play a role [8].
Tibial spine fractures occur in approximately $5 \%$ of adults with traumatic ACL insufficiency. The ACL insertion usually takes place immediately lateral and anterior to the tibial spine. For this reason, tibial spine fractures can be seen in patients with a normally functioning ACL. Tibial spine avulsion resulting in ACL insufficiency is usually related to a hyperextension injury mechanism. In children, tibial spine fractures are often isolated, while in adults the injury is frequently associated to high-energy injuries [55].

In addition, there are five specific fractures that are statistically associated with ACL injuries and should also be taken into account (table 5.1) $[7,16]$.

One study reported that kissing bone bruises on the anterior femur and tibia suggest a hyperextension mechanism and were found in association with ACL tears in approximately $50 \%$ [54]. Avulsion fractures of the proximal fibula,

Table 5.1 Fractures commonly associated with ACL injury

Segond fracture (high probability of ACL injury)
$\begin{aligned} & \text { Deep-lateral femoral-notch sign fracture (high } \\ & \text { probability of ACL injury) }\end{aligned}$
Tibial spine avulsion fracture (intermediate probability
of ACL injury)
Fracture of the posterolateral corner of the tibia
(intermediate probability of ACL injury)
Arcuate fibular head fracture (intermediate probability
of ACL injury)
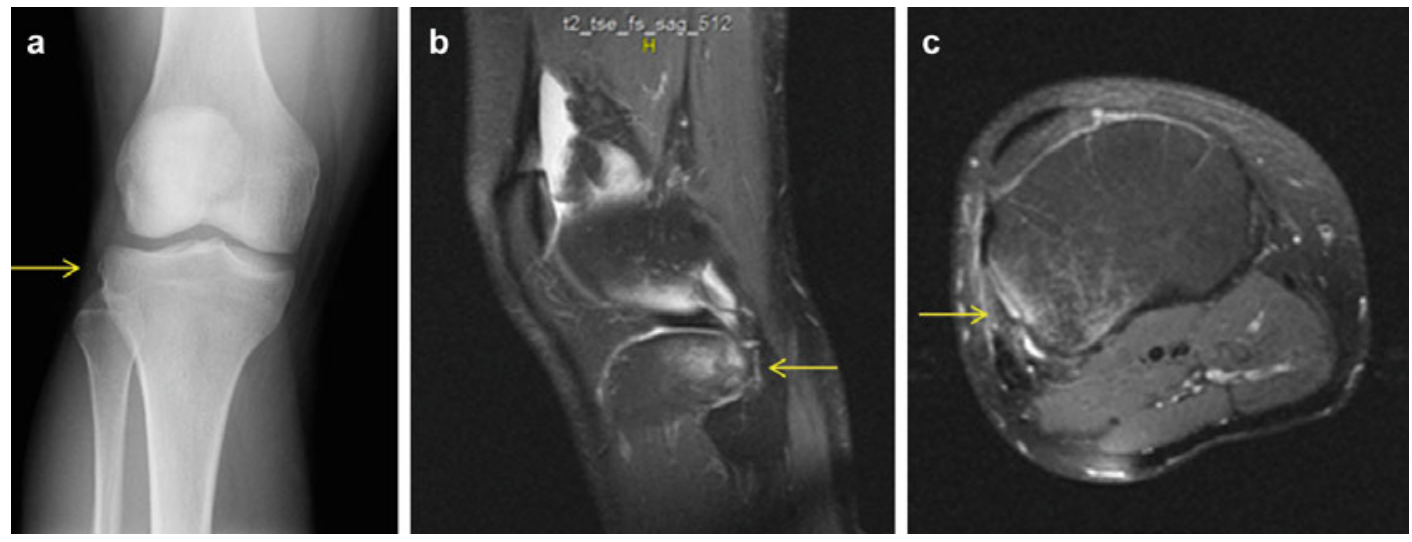

Fig. 5.2 Example of Segond fracture is difficult to identify on radiographs (yellow arrows) (a) but better clarified on MRI T2 sagittal view (b) and axial view (c) 
also known as the arcuate sign, can indicate a hyperextension/varus knee injury which usually may affect the lateral collateral ligament complex, and the ACL might also be injured [22]. In severe hyperextension injuries, the posterior cruciate ligament might be damaged, and even popliteal neurovascular injuries can occur [63].

\subsubsection{Chronic ACL Tear}

Chronic ACL ruptures are often associated to meniscal injuries and secondary osteoarthritis. The signs of ACL injury are basically the same as in the acute setting except that bone bruises and edema are usually no longer visible and T1-weighted sequences are of greater importance [57].

A fragmented ACL is the most common MRI finding in the case of a chronic injury [57]. Complete non-visualization of the ACL may also occur and include the "empty notch" sign [45].

The chronically torn ACL may attach to the posterior cruciate ligament (the so-called ACL on PCL) [52]. This phenomenon is more often noticed during arthroscopic observation and is less frequently visible on MRI [52]. The chronic non-displaced ruptured ACL might have a normal appearance once mature collagenous scarring is difficult to distinguish from the normal collagenous hypointense ligament [57].

In the presence of a positive clinical assessment (positive Lachman or pivot shift test result), a negative MRI should be interpreted as a possible false negative.

\subsubsection{Partial ACL Tear}

Partial ruptures of the ACL account for 10-43\% of all ACL injuries [15, 29, 37, 48] and have reported an even higher percentage in the pediatric population [43]. While MRI is effective in differentiating the normal from abnormal ACL, it is less reliable in terms of the diagnosis of partial ruptures [28]. Even 3-tesla MRI devices have failed to overcome this limitation $[58,59]$.

\subsection{Dynamic and Objective MRI Assessment of the Knee: Porto-Knee Testing Device (PKTD)}

The PKTD (Fig. 5.3) is a knee laxity-testing device designed for the measurement of anterior-posterior tibial translation and rotational laxity of the knee during an MRI examination [12]. This way it combines the assessment of "anatomy" and "function" during the same examination [40].
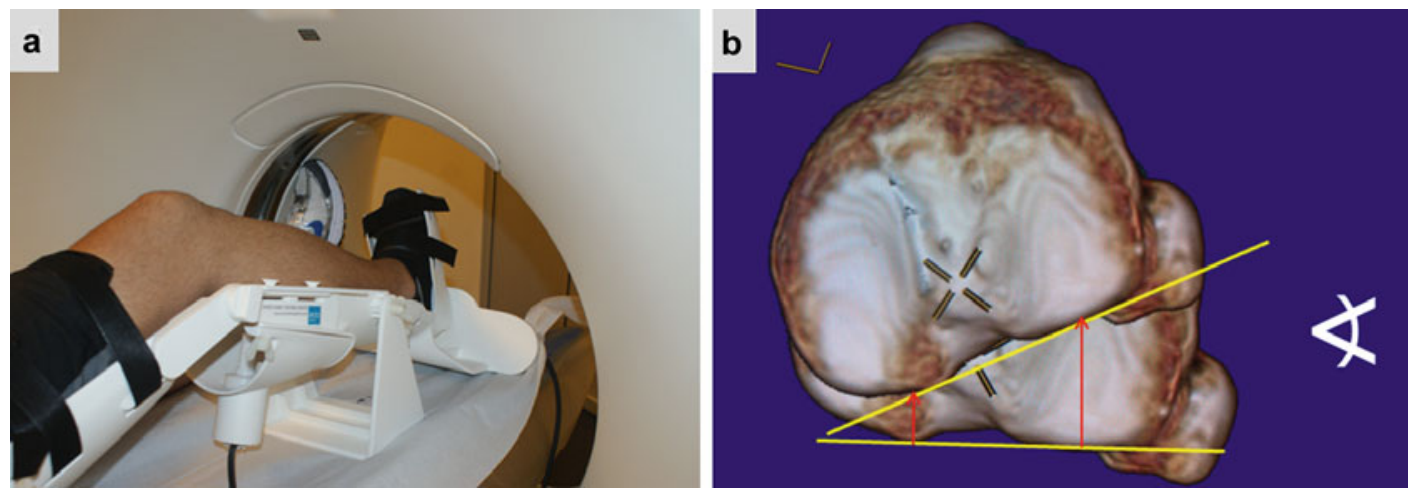

Fig. 5.3 Porto-knee testing device $\left(\mathrm{PKTD}^{\circledR}\right)$ inside MRI equipment (a); CT 3D axial view representation of tibial internal rotation and anterior translation after load application by the PKTD (b) 
PKTD is built on polyurethane which permits it to be used during MRI scans. The knee is placed under stress caused by the inflation of pneumatic cuffs permitting the examiner to control the magnitude of load transmission up to $46.7 \times 10^{3} \mathrm{~N} / \mathrm{m}^{2}$ applied in the posterior proximal calf region.

The PKTD enables the examiner to study at different degrees of knee flexion and different degrees of external/internal rotation as decided by the footplate. When required, it can also be used for evaluation of PCL injuries (Fig. 5.4). This is done by changing the position of the cuff, thus transmitting force to be applied to the anterior aspect of the tibia in a posterior direction. The study of rotational laxity is possible once the MRI images are acquired with 1-mm spacing and 3D reconstruction.

The measurement (in $\mathrm{mm}$ ) is performed using a line that is perpendicular to the tibial slope crossing the most posterior point of the tibial plateau and its distance to a parallel line crossing the most posterior point of the femoral condyle. This process is repeated with or without pressure for medial and lateral compartments, with or without rotation, identifying the same points as the bony landmarks (Fig. 5.5).

The amount of anterior translation, in millimeters, of the medial and lateral tibial plateaus with different combination of rotation is calculated by the difference of each of the two points (without and with pressure) (Fig. 5.6). The method can include the assessment of ACLdeficient knees alone or side-to-side comparison. Axial images can quantify the angles relative to the posterior intercondylar line and the posterior tibial line in degrees (Figs. 5.4 and 5.6). This is another aspect of assessment of rotational laxity in MRI evaluation currently under intense research.

It has been clinically demonstrated that PKTD-MRI method is reliable in the assessment of anterior-posterior translation (comparing to KT-1000) and rotatory laxity (compared with lateral pivot shift under anesthesia) of the ACLdeficient knee.

It has also shown capacity to identify partial ruptures (confirmed later by arthroscopic

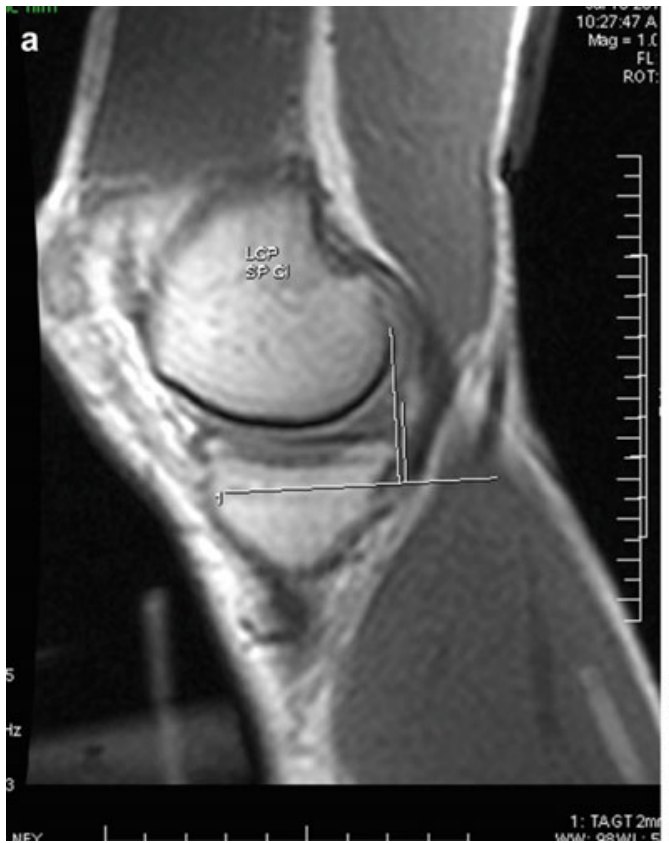

Fig. 5.4 MRI-PKTD ${ }^{\circledR}$ evaluation of a patient with posterior cruciate ligament rupture: (a) sagittal view without load, distance between medial posterior condyle and medial

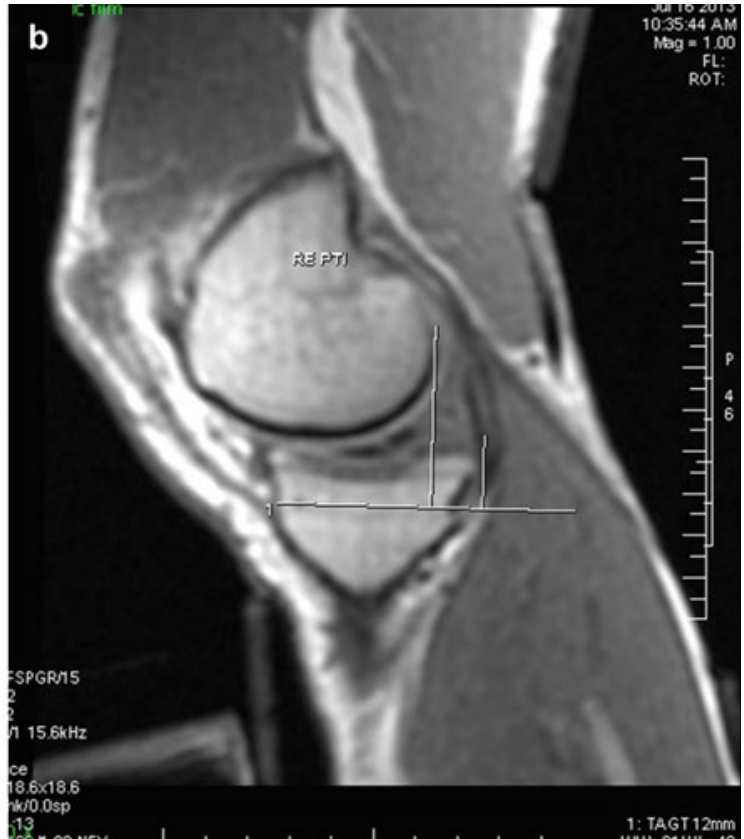

tibial plateau; (b) sagittal view with the load directed posteriorly and with external rotation, distance between medial posterior condyle and medial tibial plateau 



Fig. 5.5 CT 3D representation of the effect of PKTD ${ }^{\circledR}$ effect on anterior translation for medial compartment $(\mathbf{a}, \mathbf{b})$ and lateral compartment $(\mathbf{c}, \mathbf{d})$ 

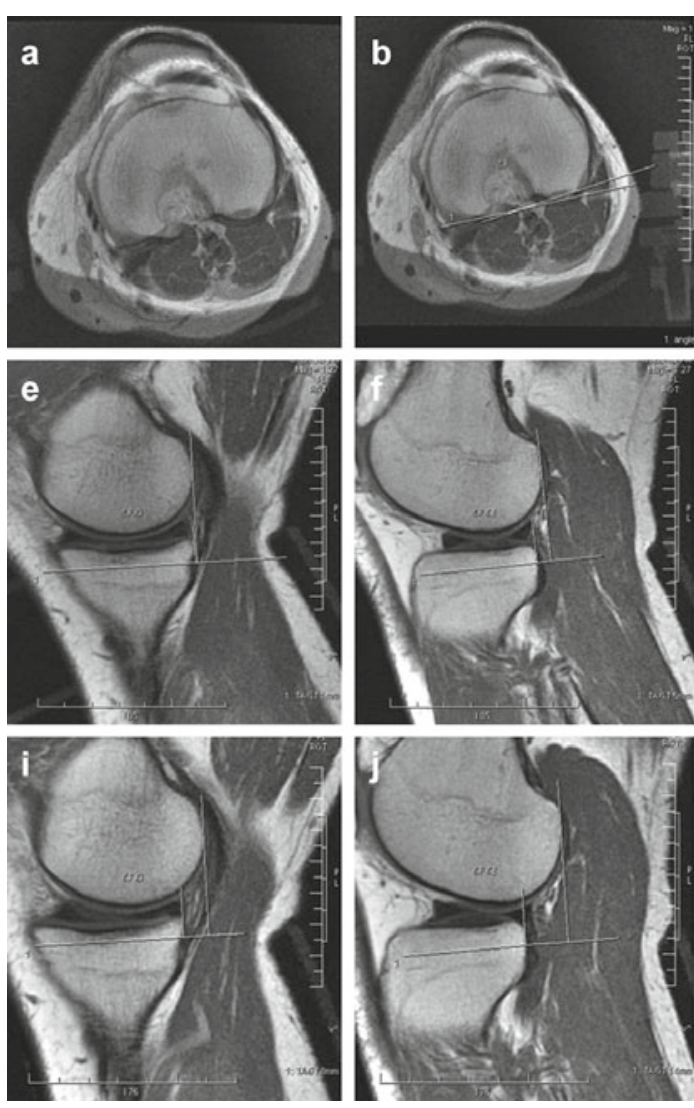

Fig. 5.6 MRI-PKTD ${ }^{\circledR}$ evaluation of a patient with ACL rupture: (a) choice of the adequate image for bony landmarks; (b) posterior intercondylar line and posterior tibial line without pressure $\left(5^{\circ}\right)$; (c) angle with load application in anterior direction and external rotation $\left(3^{\circ}\right)$; (d) angle with load application in anterior direction and internal rotation $\left(12^{\circ}\right)$; (e) sagittal view without load, distance between medial posterior condyle and medial tibial plateau $(1 \mathrm{~mm})$; (f) sagittal view without pressure, distance between lateral posterior condyle and lateral tibial plateau $(5 \mathrm{~mm})$; (g) sagittal view without anterior pressure but with external rotation, distance between medial posterior condyle and medial tibial
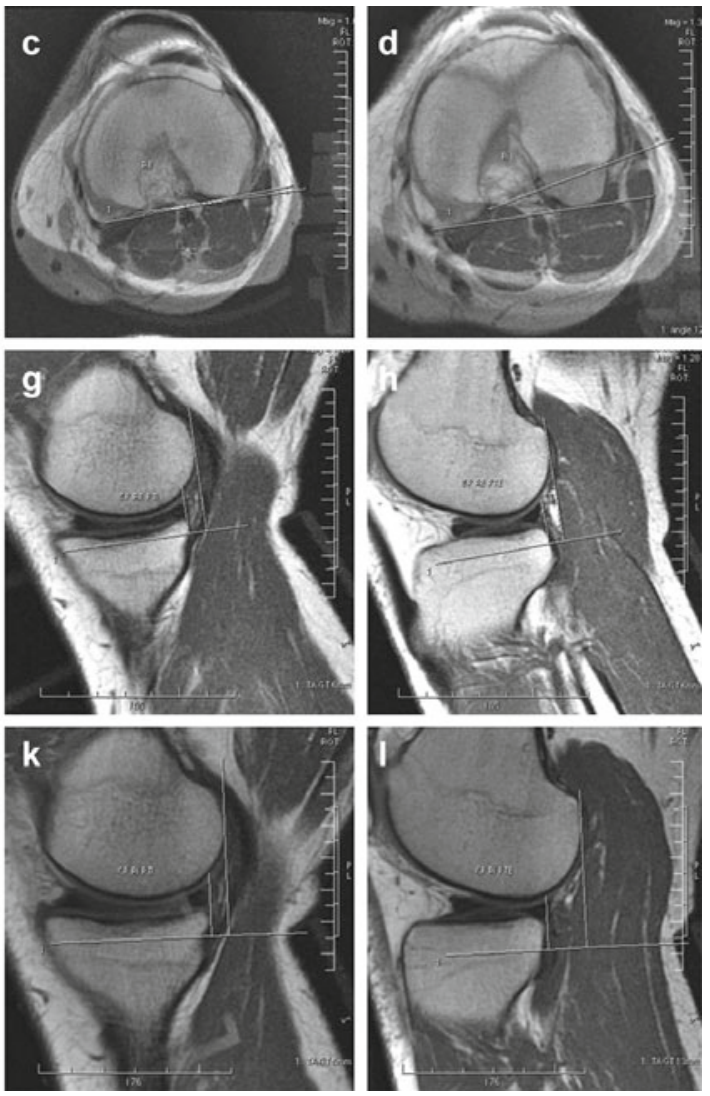

plateau $(6 \mathrm{~mm})$; (h) sagittal view without anterior pressure but with external rotation, distance between lateral posterior condyle and lateral tibial plateau (6 mm); (i) sagittal view with anterior pressure, distance between medial posterior condyle and medial tibial plateau (8 $\mathrm{mm})$; (j) sagittal view with anterior load, distance between lateral posterior condyle and lateral tibial plateau $(14 \mathrm{~mm})$; (k) sagittal view with anterior load and internal rotation, distance between medial posterior condyle and medial tibial plateau $(5 \mathrm{~mm})$; (l) sagittal view with anterior load and internal rotation, distance between lateral posterior condyle and lateral tibial plateau $(13 \mathrm{~mm})$ 
findings). However, by putting stress on the ACL during the examination, the method permits to simultaneously evaluate the mechanical behavior of partial ruptures and improve the visualization of "biologic"/signal features of the ruptured and the remaining bundle (Fact Box 2).

\section{Fact Box 2. Advantages of PKTD: MRI Evaluation Protocol}

- Preserves all anatomical possibilities of MRI

- Enables knee assessment at several degrees of flexion

- Enables anterior-posterior and rotational forces during the exam

- Uses bony landmarks to measure translation

- Enables objective quantification of the amount of produced translation for medial and lateral compartments

- Dynamic evaluation assists in evaluation of partial tears

- Enables assessment of posterior instability (posterior cruciate ligament or combined injuries).

Ongoing research is now focused to improve the possibilities of this method to identify populations with increased risk factors for ACL rupture [40].

\section{Conclusion}

MRI protocols for knee study should include spin echo or fat-saturated fast spin echo images in all three planes, including T1- and T2-weighted sagittal images. Currently, sagittal images are more frequently obtained in the true orthogonal plane. The examiner must be familiar with normal and abnormal appearances of the ACL in all planes. Primary and secondary signs of ACL rupture should be scrutinized. Frequently associated fractures/patterns should also be checked. One should be aware of the lower accuracy of
MRI for partial tears and chronic tears. There is much room for progress in MRI investigations of the ACL. Continued technological advances in imaging instrumentation, software, and contrast agents will probably result in faster and more informative MRI examinations in the near future. New types of sequences are emerging every year. Moreover, dynamic MRI evaluation is under development in order to become easier, faster, and more useful compared with the current static imaging.

\section{References}

1. Araujo PH, Kfuri Junior M, Ohashi B, Hoshino Y, Zaffagnini S, Samuelsson K, Karlsson J, Fu F, Musahl V (2014) Individualized ACL reconstruction. Knee Surg Sports Traumatol Arthrosc 22(9):1966-1975. doi:10.1007/s00167-014-2928-2

2. Arilla FV, Yeung M, Bell K, Rahnemai-Azar AA, Rothrauff BB, Fu FH, Debski RE, Ayeni OR, Musahl V (2015) Experimental execution of the simulated Pivot-Shift Test: a systematic review of techniques. Arthrosc 31:2445-2454. doi:10.1016/j. arthro.2015.06.027

3. Behairy NH, Dorgham MA, Khaled SA (2009) Accuracy of routine magnetic resonance imaging in meniscal and ligamentous injuries of the knee: comparison with arthroscopy. Int Orthop 33(4):961-967. doi:10.1007/s00264-008-0580-5

4. Benjaminse A, Gokeler A, van der Schans CP (2006) Clinical diagnosis of an anterior cruciate ligament rupture: a meta-analysis. J Orthop Sports Phys Ther 36(5):267-288. doi:10.2519/jospt.2006.2011

5. Bjornsson H, Desai N, Musahl V, Alentorn-Geli E, Bhandari M, Fu F, Samuelsson K (2015) Is doublebundle anterior cruciate ligament reconstruction superior to single-bundle? a comprehensive systematic review. Knee Surg Sports Traumatol Arthrosc 23(3):696-739. doi:10.1007/s00167-013-2666-X

6. Brandon ML, Haynes PT, Bonamo JR, Flynn MI, Barrett GR, Sherman MF (2006) The association between posterior-inferior tibial slope and anterior cruciate ligament insufficiency. Arthrosc 22(8):894899. doi:10.1016/j.arthro.2006.04.098

7. Brandser EA, Riley MA, Berbaum KS, el-Khoury GY, Bennett DL (1996) MR imaging of anterior cruciate ligament injury: independent value of primary and secondary signs. AJR Am J Roentgenol 167((1):121126. doi:10.2214/ajr.167.1.8659355

8. Campos JC, Chung CB, Lektrakul N, Pedowitz R, Trudell D, Yu J, Resnick D (2001) Pathogenesis of the segond fracture: anatomic and MR imaging evidence 
of an iliotibial tract or anterior oblique band avulsion. Radiology 219(2):381-386. doi:10.1148/radiology.21 9.2.r01ma23381

9. Chan WP, Peterfy C, Fritz RC, Genant HK (1994) MR diagnosis of complete tears of the anterior cruciate ligament of the knee: importance of anterior subluxation of the tibia. AJR Am J Roentgenol 162(2):355360. doi:10.2214/ajr.162.2.8310927

10. Citak M, Suero EM, Rozell JC, Bosscher MR, Kuestermeyer J, Pearle AD (2011) A mechanized and standardized pivot shifter: technical description and first evaluation. Knee Surg Sports Traumatol Arthrosc 19(5):707-711. doi:10.1007/ s00167-010-1289-8

11. DeFranco MJ, Bach BR Jr (2009) A comprehensive review of partial anterior cruciate ligament tears. J Bone Joint Surg Am 91(1):198-208. doi:10.2106/ JBJS.H.00819

12. Espregueira-Mendes J, Pereira H, Sevivas N, Passos C, Vasconcelos JC, Monteiro A, Oliveira JM, Reis RL (2012) Assessment of rotatory laxity in anterior cruciate ligament-deficient knees using magnetic resonance imaging with Porto-knee testing device. Knee Surg Sports Traumatol Arthrosc 20(4):671-678. doi:10.1007/s00167-012-1914-9

13. Falchook FS, Tigges S, Carpenter WA, Branch TP, Stiles RG (1996) Accuracy of direct signs of tears of the anterior cruciate ligament. Can Assoc Radiol J (Journal l'Association canadienne des radiologistes) 47(2):114-120

14. Fitzgerald SW, Remer EM, Friedman H, Rogers LF, Hendrix RW, Schafer MF (1993) MR evaluation of the anterior cruciate ligament: value of supplementing sagittal images with coronal and axial images. AJR Am J Roentgenol 160(6):1233-1237. doi:10.2214/ ajr.160.6.8498224

15. Fruensgaard S, Johannsen HV (1989) Incomplete ruptures of the anterior cruciate ligament. J Bone Joint Surg 71(3):526-530

16. Giaconi JC, Allen CR, Steinbach LS (2009) Anterior cruciate ligament graft reconstruction: clinical, technical, and imaging overview. Top Magn Reson Imaging : TMRI 20(3):129-150. doi:10.1097/ RMR.0b013e3181d657a7

17. Grzelak P, Podgorski MT, Stefanczyk L, Domzalski M (2015) Ultrasonographic test for complete anterior cruciate ligament injury. Indian J Orthop 49(2):143149. doi:10.4103/0019-5413.152432

18. Hoshino Y, Kuroda R, Nagamune K, Araki D, Kubo S, Yamaguchi M, Kurosaka M (2012) Optimal measurement of clinical rotational test for evaluating anterior cruciate ligament insufficiency. Knee Surg Sports Traumatol Arthrosc 20(7):1323-1330. doi:10.1007/ s00167-011-1643-5

19. Hoshino Y, Musahl V, Irrgang JJ, Lopomo N, Zaffagnini S, Karlsson J, Kuroda R, Fu FH (2015) Quantitative evaluation of the Pivot Shift - relationship to clinical Pivot Shift Grade: a prospective international multicenter study. Orthop J Sports Med 3(2 suppl):56-72. doi:10.1177/2325967115s00108
20. Isberg J, Faxen E, Brandsson S, Eriksson BI, Karrholm J, Karlsson J (2006) KT-1000 records smaller side-to-side differences than radiostereometric analysis before and after an ACL reconstruction. Knee Surg Sports Traumatol Arthrosc 14(6):529-535. doi:10.1007/s00167-006-0061-6

21. Jonsson H, Riklund-Ahlstrom K, Lind J (2004) Positive pivot shift after ACL reconstruction predicts later osteoarthrosis: 63 patients followed 5-9 years after surgery. Acta Orthop Scand 75(5):594-599. doi:10.1080/00016470410001484

22. Juhng SK, Lee JK, Choi SS, Yoon KH, Roh BS, Won JJ (2002) MR evaluation of the "arcuate" sign of posterolateral knee instability. AJR Am J Roentgenol 178(3):583-588. doi:10.2214/ajr.178.3.1780583

23. Kato Y, Maeyama A, Lertwanich $P$, Wang JH, Ingham SJ, Kramer S, Martins CQ, Smolinski P, Fu FH (2013) Biomechanical comparison of different graft positions for single-bundle anterior cruciate ligament reconstruction. Knee Surg Sports Traumatol Arthrosc 21(4):816-823. doi:10.1007/s00167-012-1951-4

24. Kocher MS, Steadman JR, Briggs KK, Sterett WI, Hawkins RJ (2004) Relationships between objective assessment of ligament stability and subjective assessment of symptoms and function after anterior cruciate ligament reconstruction. Am J Sports Med 32(3):629-634

25. Kothari A, Haughom B, Subburaj K, Feeley B, Li X, Ma CB (2012) Evaluating rotational kinematics of the knee in ACL reconstructed patients using 3.0 Tesla magnetic resonance imaging. Knee 19(5):648-651. doi:10.1016/j.knee.2011.12.001

26. Kuroda R, Hoshino Y, Kubo S, Araki D, Oka S, Nagamune K, Kurosaka M (2011) Similarities and Differences of Diagnostic Manual Tests for Anterior Cruciate Ligament Insufficiency: A Global Survey and Kinematics Assessment. Am J Sports Med. doi:10.1177/0363546511423634, 0363546511423634 [pii]

27. Lane CG, Warren R, Pearle AD (2008) The pivot shift. J Am Acad Orthop Surg 16(12):679-688, doi: 16/12/679 [pii]

28. Lawrance JA, Ostlere SJ, Dodd CA (1996) MRI diagnosis of partial tears of the anterior cruciate ligament. Injury 27(3):153-155

29. Lee K, Siegel MJ, Lau DM, Hildebolt CF, Matava MJ (1999) Anterior cruciate ligament tears: MR imagingbased diagnosis in a pediatric population. Radiology 213(3):697-704. doi:10.1148/radiology.213.3.r9 $9 \mathrm{dc} 26697$

30. Lee SY, Matsui N, Yoshida K, Doi R, Matsushima S, Wakami T, Fujii M, Yoshiya S, Kurosaka M, Yamamoto $\mathrm{T}$ (2005) Magnetic resonance delineation of the anterior cruciate ligament of the knee: flexed knee position within a surface coil. Clin Imaging 29(2):117-122. doi:10.1016/j. clinimag.2004.04.024

31. Leitze Z, Losee RE, Jokl P, Johnson TR, Feagin JA (2005) Implications of the pivot shift in the ACLdeficient knee. Clin Orthop Relat Res 436:229-236 
32. Mellado JM, Calmet J, Olona M, Gine J, Sauri A (2004) Magnetic resonance imaging of anterior cruciate ligament tears: reevaluation of quantitative parameters and imaging findings including a simplified method for measuring the anterior cruciate ligament angle. Knee Surg Sports Traumatol Arthrosc 12(3):217-224. doi:10.1007/s00167-003-0431-2

33. Mink JH, Levy T, Crues JV 3rd (1988) Tears of the anterior cruciate ligament and menisci of the knee: MR imaging evaluation. Radiology 167(3):769-774. doi:10.1148/radiology.167.3.3363138

34. Muller B, Hofbauer M, Rahnemai-Azar AA, Wolf M, Araki D, Hoshino Y, Araujo P, Debski RE, Irrgang JJ, Fu FH, Musahl V (2015) Development of computer tablet software for clinical quantification of lateral knee compartment translation during the pivot shift test. Comput Methods Biomech Biomed Engin 19:112. doi:10.1080/10255842.2015.1006210

35. Murphy BJ, Smith RL, Uribe JW, Janecki CJ, Hechtman KS, Mangasarian RA (1992) Bone signal abnormalities in the posterolateral tibia and lateral femoral condyle in complete tears of the anterior cruciate ligament: a specific sign? Radiology 182(1):221224. doi:10.1148/radiology.182.1.1727286

36. Musahl V, Voos J, O'Loughlin PF, Stueber V, Kendoff D, Pearle AD (2010) Mechanized pivot shift test achieves greater accuracy than manual pivot shift test. Knee Surg Sports Traumatol Arthrosc 18(9):12081213. doi:10.1007/s00167-009-1004-9

37. Noyes FR, Mooar LA, Moorman CT 3rd, McGinniss GH (1989) Partial tears of the anterior cruciate ligament. progression to complete ligament deficiency. J Bone Joint Surg 71(5):825-833

38. Ochi M, Adachi N, Deie M, Kanaya A (2006) Anterior cruciate ligament augmentation procedure with a 1-incision technique: anteromedial bundle or posterolateral bundle reconstruction. Arthroscopy 22(4):463 e461-465. doi:10.1016/j.arthro.2005.06.034, S0749-8063(05)01560-4 [pii]

39. Ohashi B, Ward J, Araujo P, Kfuri M, Pereira H, Espregueira-Mendes J, Musahl V (2014) Partial ACL Ruptures: knee laxity measurements and Pivot Shift. In: Doral MN, Karlsson J (eds) Sports injuries. Springer, Berlin/Heidelberg, pp 1-16. doi:10.1007/978-3-642-36801-1_85-1

40. Pereira H, Fernandes M, Pereira R, Jones H, Vasconcelos JC, Oliveira JM, Reis RL, Musahl V, Espregueira-Mendes J (2014) ACL injuries identifiable for Pre-participation imagiological analysis: risk factors. In: Doral MN, Karlsson J (eds) Sports injuries. Springer, Berlin/Heidelberg, pp 1-15. doi:10.1007/978-3-642-36801-1_80-1

41. Pereira H, Sevivas N, Pereira R, Monteiro A, Oliveira JM, Reis RL, Espregueira-Mendes J (2012) New tools for diagnosis, assessment of surgical outcome and follow-up. In: Hernández JA, Monllau JC (eds) Lesiones ligamentosas de la rodilla. Marge Médica Books Barcelona, Spain, pp 185-198

42. Pereira H, Sevivas N, Pereira R, Monteiro A, Sampaio R, Oliveira J, Reis R, Espregueira-Mendes J (2014) Systematic approach from Porto School. In: Siebold
R, Dejour D, Zaffagnini S (eds) Anterior cruciate ligament reconstruction. Springer, Berlin/Heidelberg, pp 367-386. doi:10.1007/978-3-642-45349-6_34

43. Prince JS, Laor T, Bean JA (2005) MRI of anterior cruciate ligament injuries and associated findings in the pediatric knee: changes with skeletal maturation. AJR Am J Roentgenol 185(3):756-762. doi:10.2214/ ajr.185.3.01850756

44. Prins M (2006) The Lachman test is the most sensitive and the pivot shift the most specific test for the diagnosis of ACL rupture. Aust J Physiother 52(1):66. doi:http:// dx.doi.org/10.1016/S0004-9514(06)70069-1

45. Remer EM, Fitzgerald SW, Friedman H, Rogers LF, Hendrix RW, Schafer MF (1992) Anterior cruciate ligament injury: MR imaging diagnosis and patterns of injury. Radiogr Rev Publ Radiol Soc N Am, Inc 12(5):901-915. doi:10.1148/ radiographics.12.5.1529133

46. Resnick D (1995) Diagnosis of bone and joint disorders. 3rd edn. WB Saunders Co, Philadelphia

47. Robertson PL, Schweitzer ME, Bartolozzi AR, Ugoni A (1994) Anterior cruciate ligament tears: evaluation of multiple signs with MR imaging. Radiology 193(3):829-834.doi:10.1148/radiology.193.3.7972833

48. Roychowdhury S, Fitzgerald SW, Sonin AH, Peduto AJ, Miller FH, Hoff FL (1997) Using MR imaging to diagnose partial tears of the anterior cruciate ligament: value of axial images. AJR Am J Roentgenol 168(6):1487-1491. doi:10.2214/ajr.168.6.9168712

49. Rubin DA, Kettering JM, Towers JD, Britton CA (1998) MR imaging of knees having isolated and combined ligament injuries. AJR Am J Roentgenol 170(5):1207-1213. doi:10.2214/ajr.170.5.9574586

50. Sonnery-Cottet B, Lavoie F, Ogassawara R, Scussiato RG, Kidder JF, Chambat P (2010) Selective anteromedial bundle reconstruction in partial ACL tears: a series of 36 patients with mean 24 months follow-up. Knee Surg Sports Traumatol Arthrosc 18(1):47-51. doi:10.1007/s00167-009-0855-4

51. Staubli HU, Noesberger B, Jakob RP (1992) Stress radiography of the knee. Cruciate ligament function studied in 138 patients. Acta Orthop Scand Suppl 249:1-27

52. Stoller D (1997) Magnetic resonance imaging in orthopaedics and sports medicine. 2nd edn. Lippincott-Raven, Philadelphia

53. Swain MS, Henschke N, Kamper SJ, Downie AS, Koes BW, Maher CG (2014) Accuracy of clinical tests in the diagnosis of anterior cruciate ligament injury: a systematic review. Chiropr Man Therap 22:25. doi:10.1186/s 12998-014-0025-8

54. Terzidis IP, Christodoulou AG, Ploumis AL, Metsovitis SR, Koimtzis M, Givissis P (2004) The appearance of kissing contusion in the acutely injured knee in the athletes. Br J Sports Med 38(5):592-596. doi:10.1136/bjsm.2003.006718

55. Toye LR, Cummings DP, Armendariz G (2002) Adult tibial intercondylar eminence fracture: evaluation with MR imaging. Skeletal Radiol 31(1):46-48. doi:10.1007/s00256-001-0440-5

56. Tung GA, Davis LM, Wiggins ME, Fadale PD (1993) Tears of the anterior cruciate ligament: primary and sec- 
ondary signs at MR imaging. Radiology 188(3):661667. doi:10.1148/radiology.188.3.8351329

57. Vahey TN, Broome DR, Kayes KJ, Shelbourne KD (1991) Acute and chronic tears of the anterior cruciate ligament: differential features at $\mathrm{MR}$ imaging. Radiology 181(1):251-253. doi:10.1148/ radiology.181.1.1887042

58. Van Dyck P, De Smet E, Veryser J, Lambrecht V, Gielen JL, Vanhoenacker FM, Dossche L, Parizel PM (2012) Partial tear of the anterior cruciate ligament of the knee: injury patterns on MR imaging. Knee Surg Sports Traumatol Arthrosc 20(2):256-261. doi:10.1007/s00167-011-1617-7

59. Van Dyck P, Vanhoenacker FM, Gielen JL, Dossche L, Van Gestel J, Wouters K, Parizel PM (2011) Three tesla magnetic resonance imaging of the anterior cruciate ligament of the knee: can we differentiate complete from partial tears? Skeletal Radiol 40(6):701-707. doi:10.1007/s00256-010-1044-8

60. Van Dyck P, Vanhoenacker FM, Lambrecht V, Wouters K, Gielen JL, Dossche L, Parizel PM (2013) Prospective comparison of 1.5 and 3.0-T MRI for evaluating the knee menisci and ACL. J Bone Joint Surg Am 95(10):916-924. doi:10.2106/JBJS.L.01195

61. Winters K, Tregonning R (2005) Reliability of magnetic resonance imaging of the traumatic knee as determined by arthroscopy. N Z Med J 118(1209):U1301

62. Yasuda K, van Eck CF, Hoshino Y, Fu FH, Tashman S (2011) Anatomic single- and double-bundle anterior cruciate ligament reconstruction, part 1: basic science. Am J Sports Med 39(8):1789-1799. doi:10.1177/0363546511402659

63. Yu JS, Goodwin D, Salonen D, Pathria MN, Resnick D, Dardani M, Schweitzer M (1995) Complete dislocation of the knee: spectrum of associated soft-tissue injuries depicted by MR imaging. AJR Am J Roentgenol 164(1):135-139. doi:10.2214/ ajr.164.1.7998526

64. Zaffagnini S, Bignozzi S, Martelli S, Imakiire N, Lopomo N, Marcacci M (2006) New intraoperative protocol for kinematic evaluation of ACL reconstruction: preliminary results. Knee Surg Sports Traumatol Arthrosc 14(9):811-816. doi:10.1007/ s00167-006-0057-2 